\title{
Untreated borderline-leprosy in the ulnar nerve: light and electron microscopical studies
}

\author{
P VIEREGGE, ${ }^{*}$ V REINHARDT, ${ }^{*}$ L GERHARD,* \\ U SCHLIWINSKI* \& J R JÖRG $\dagger$ \\ *Institute of Neuropathology; $\uparrow$ Neurological Department; Klinikum \\ of the Gesamthochschule, Hufelandstr. 55, D-4300 Essen, Federal \\ Republic of Germany
}

\section{Accepted for publication 9 July 1984}

\begin{abstract}
Summary A case of a 41-year-old Indian patient with an untreated neuritis of multiplex type is presented. Clinical and microscopical examination revealed borderline-leprosy.

The difficulties in discriminating between changes due to the primary inflammatory process and secondary changes such as oedema, fibrosis, vascular occlusion and compressive factors, are discussed. Detailed morphological data from both light and electron microscopical studies are presented.
\end{abstract}

\section{Introduction}

Early lesions in leprosy, concerning especially the role of Schwann cell, have been studied to evaluate the exact mode of the spread of infection. ${ }^{1.2}$ Apart from reactional states, secondary changes of the nerve like oedema, fibrosis, vascular occlusion and compressive factors in untreated borderline-patients may complicate the clinico-pathological picture, which itself is unstable due to the labile immunological response.

The present report demonstrates the difficulties in discrimination between the primary inflammatory process and the above secondary changes in peripheral nerves. Morphological data, from both light and electron microscopy in an untreated patient with borderline-leprosy, are presented.

\section{Case report}

A 41-year-old Indian physician noted tingling and prickling in the right 4 th and 5 th finger ten days after he had arrived in Germany. Some days later, increasing 
pains occurred together with a progressive weakness of those fingers. The patient observed a thickened $N$. ulnaris in the upper arm region. Pressure on this nerve caused painful paraesthesias, especially in the finger tips. Later flushing, itching and swelling occurred in the mid region of the 5th finger. No previous neurological illness was known except for a right hemianopia since childhood. No previous antileprosy treatment was given.

On admission the right ulnar nerve was palpable as a thickened, indurated cord extending $15 \mathrm{~cm}$ upwards from the sulcus $n$. ulnaris to the upper arm. Distal pressure of the sulcus caused intense, irritating pain diffusely in the lower arm and hand. There was a hypaesthesia for all modalities in the ulnar part of 4 th and the entire 5th finger extending up to the wrist. A dissociated perception disorder also on the tip of the 3rd finger was found. Muscle weakness was severe in the ulnar $\mathrm{Mm}$. lumbricales, the $\mathrm{Mm}$. interossei, and the $\mathrm{M}$. abd. dig. $\mathrm{V}$, less severe in the M. flex. carpi uln., M. flex. dig. prof., M. opp. dig. V, M. add. poll., and $M$. flex. poll. brev. The M. ext. carpi uln. and M. ext. dig. comm. showed moderate weakness. There was a flush of the ulnar region of the dorsal right hand and the area of metacarpo-phalangeal joint of the 5th finger was swollen. On the back, a 5:5 cm hypo-pigmented area with irregular outlines was seen above the right buttock.

Nerve conduction velocity was normal in the right $N$. medianus and the left $N$. ulnaris. In the right $N$. ulnaris it was moderately reduced in the lower arm region, but severely reduced in the sulcus and upper arm region. EMG showed complete denervation of $\mathrm{Mm}$. interossei. Severe neurogenic change was observed in the $\mathrm{M}$. abd. dig. V. and less pronounced in the M. flex. carp. uln. Some neurogenic change was also seen in the M. pronator quadr. and the M. ext. carp. uln.

Eight weeks after onset an extended epineurial neurolysis of the right $N$. ulnaris was performed over a length of $20 \mathrm{~cm}$ from the proximal lower arm along the sulcus to the upper arm. Macroscopically the nerve appeared normal only at the most distal and proximal ends of the examined region. Intervening nerve tissue was grossly swollen; several fascicles were distended, yellowish-brown in colour; more proximally they appeared darkened and apparently necrotic. Tissues were taken for histological examination.

\section{Methods}

For light microscopy tissue was fixed in formalin (1:9) and embedded in paraffin wax. Sections of $18 \mu$ were examined by the following methods: HaematoxylinEosin, Elastica-van Gieson's, PAS, Sudanblack-Nuclear Fast Red, PalmgrenLuxol Fast Blue, Gram's, Ziehl-Neelsen's, Wade-Fite's, Ladewig's, and Congo Red.

For electron microscopy specimens were fixed in phosphate buffered glutaraldehyde. They were postfixed in osmiumtetroxide, dehydrated in acetone 
and embedded in araldite. Thin sections were stained with lead citrate and uranyl acetate.

Araldite-embedded semithin-sections of $1 \mu$ were stained with Methylene Blue-Azur II, $45 \mathrm{~min}$ with $2.5 \%$ basic Fuchsin at room temperature and dried on a hot plate.

\section{LIGHT MICROSCOPICAL FINDINGS}

Epineurial tissue was diffusely infiltrated by lymphocytes, few plasmocytes, and histiocytes, occasionally in perivascular arrangement.

The perineurial sheath of some preserved fascicles was sometimes slightly thickened, but otherwise normal. The perineurial sheath of the major part of the
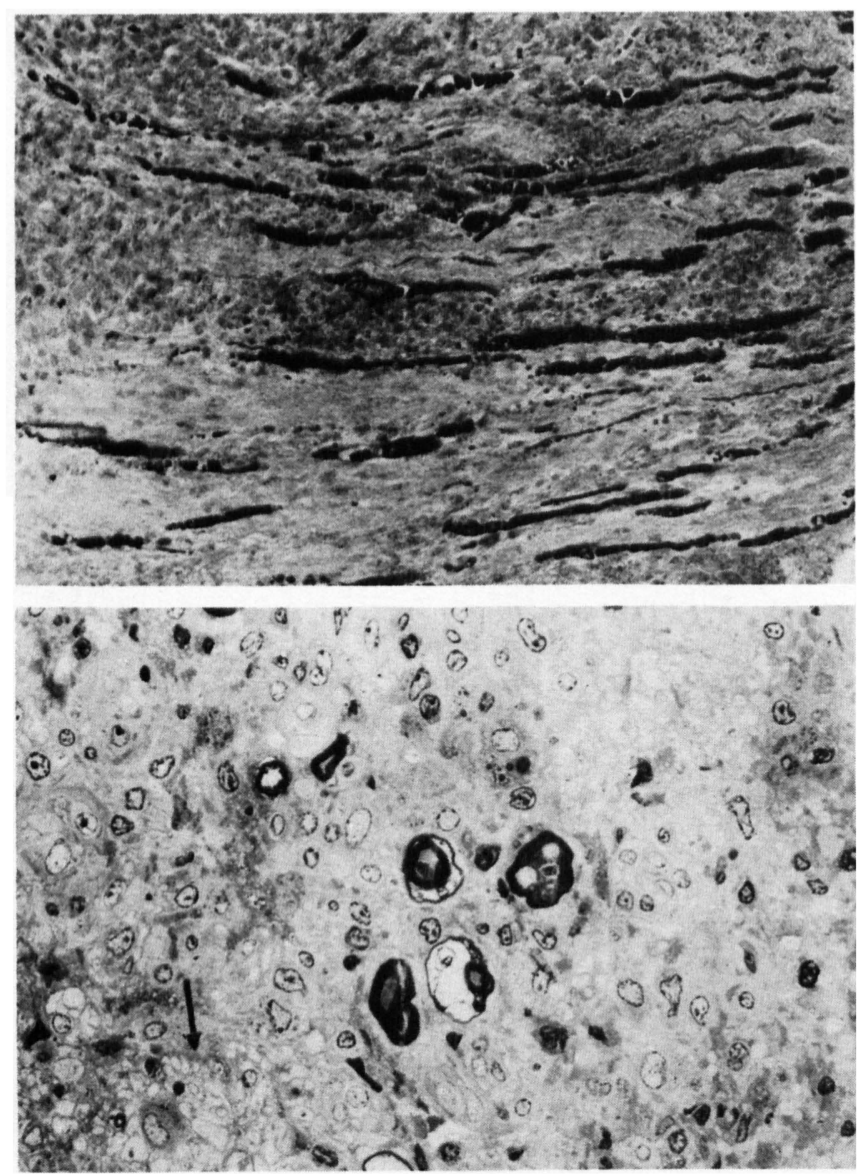

Figure 1 (a) Remnants of myelinated axons distended by strands of inflammatory cells. Balls of myelin $(\rightarrow)$. Sudanblack-Nuclear Fast Red, $(\times 160)$. (b) Semithin-section of myelinated axons surrounded by inflammatory cells and proliferated Schwann cells. Bands of Büngner $(\rightarrow) .(\times 700)$. 
fascicles was largely destroyed. Alongside these areas inflammatory granulomatous tissue stretched into the remnants of endoneurial tissue.

Neural elements were extensively distended or replaced by fibrous tissue with few scattered portions of surviving myelin sheaths and axons. The larger proportion of myelin was fragmented and disaggregated in lumps, granules, and 'balloons' (Figure 1). The majority of the remaining axons showed degenerative changes. Definitely unaffected axons were not seen. Alongside the demyelinated fibres dense infiltrates of lymphocytes, rarely plasmocytes, and histiocytes occurred, the latter often appearing as foam cells. Rarely solitary epithelioid cells were diffusely spread.

Mycobacteria were often seen in clumps in Schwann cells, and in macrophages also arranged in globi. Frequently the bacteria showed a convoy-like arrangement along the remnants of myelin sheaths. The clumps of bacteria were not usually associated with surrounding inflammatory cells. Definitely extracellular mycobacteria were not detected.

Some remyelination as well as onion-bulb-formation was observed. The number of Schwann cell nuclei and endoneurial collagenous tissue were augmented. There was no abscess or amyloid formation. One large area of focal necrosis of fibrous tissue was encountered with degenerated inflammatory and endothelial cells and the remnants of vessel walls (Figure 2a).
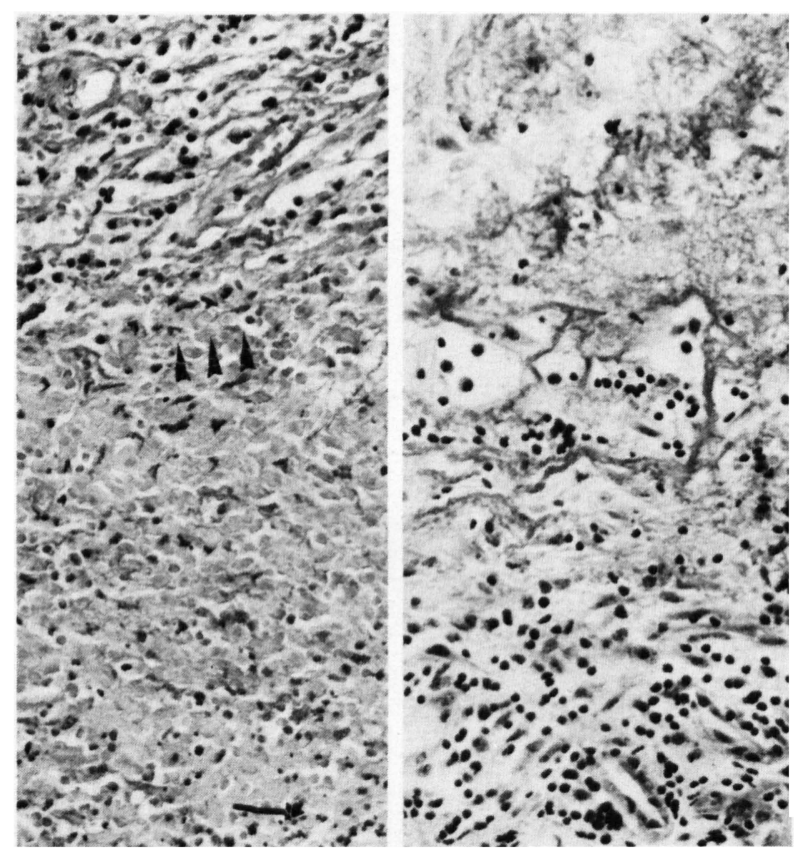

Figure 2 (a) Recent necrosis of inflammatory tissue with remnants of pycnotic nuclei $(\rightarrow)$ Border of the necrosis ( ). Elastica-van Gieson's, $(\times 320)$. (b) Fibrinous exudate in subcutaneous tissue. PAS, $(\times 320)$. 
Inside and outside the fibrous tissue the number of endothelial cells of arterioles and capillaries was raised. Their nuclei were swollen. The vessel walls often appeared thickened. To some extent this was also seen in endoneurial vessels of fascicles with a normal perineurial sheath. Lumina of endoneurial vessels within regions of destroyed perineurial sheath sometimes appeared largely narrowed or even occluded by swollen endothelial cells (Figure 3). Thrombosis was not seen. Bacteria were not aggregated in or around peri- and endoneurial vessels.

Subcutaneous areas of the specimen were partly distended by masses of fibrin which to some extent showed signs of organization (Figure 2b). Some predominantly lymphocytic infiltrates in epineurial distribution were seen. Nerve fibres and their sheaths were largely inconspicuous. No acid-fast bacilli were observed.

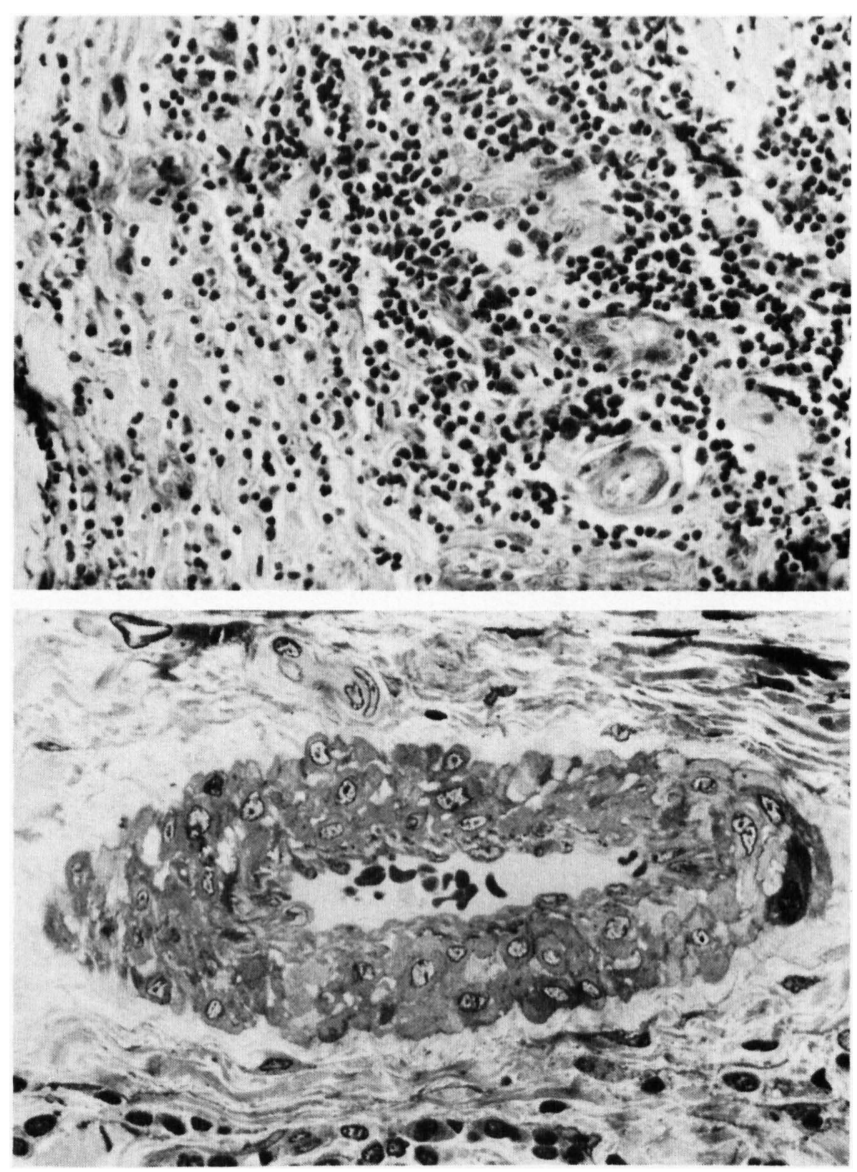

Figure 3 (a) Inflammatory cells and small proliferated vessels with heavily swollen endothelial cells. PAS, $(\times 320)$. (b) Semithin-section of a larger epineurial vessel with swelling and proliferation of endothelial cells. $(\times 700)$. 
Endothelial cells appeared to be swollen. Skin biopsies from other parts of the body revealed a non-specific dermatitis with no bacilli visible.

\section{ELECTRON MICROSCOPICAL FINDINGS}

Few nerve fascicles had an intact perineurial sheath with well-preserved myelinated fibres. The larger proportion of nerve fibres was scattered and destroyed by inflammatory cells and fibrous tissue. Breakdown and phagocytosis of myelin were frequently encountered as were swelling of cytoplasm and proliferation of Schwann cells. Their processes were frequently intertwined with bands of endoneurial collagen in a complex fashion which sometimes presented as bands of Büngner (Figure $1 \mathrm{~b}$ and $4 \mathrm{a}$ ).

Wallerian degeneration, mostly in early stages, was sometimes conspicuous. Few large unmyelinated axons were seen, that appeared to be previously myelinated. The number of mitochondria was raised in myelinated more than in unmyelinated axons. Sometimes mitochondria were swollen. There were no pathological changes in axons from areas with an intact perineurial sheath.

Acid-fast bacilli were frequently observed in Schwann cells of myelinated and unmyelinated nerve fibres, in macrophages, and in histiocytes forming globi (Figure 4a). Few bacteria were detected in endothelial cells. Rarely bacteria in vessel lumina, fibroblasts and extracellularly were seen. The bacilli were mostly arranged parallel to the course of the nerve fibre like cigarettes in a tin can, sometimes in an immediate adaxonal position. Occasionally they appeared as rods, hooks, or dots. Solitary bacteria were rare, mostly clumps of 5-15 were encountered, often engulfed by a lysosome. With only few exceptions the bacteria themselves showed degenerative changes. Their surrounding electron-transparent zone (ETZ) had an ill-defined phagosome membrane and this often was confluent with that of neighbouring bacteria. Solid staining, viable organisms were mainly seen in Schwann cell processes.

Intra-axonal bacteria, viable or degenerated, were rarely observed. The electron-dense wall of the ETZ either completely separated the axoplasm from the organism or was slightly irregular. The adjacent axoplasm looked otherwise normal (Figure 4b).

The basement membrane of vessels was swollen and partly damaged. Extraluminal erythrocytes and intraluminal macrophages harbouring mycobacteria were observed (Figure 5). In accordance with light microscopy, endothelial cells were often swollen to such an extent that they appeared to occlude the vessel lumen.

\section{Discussion}

Clinically the patient presented with a neuritis of multiplex type, the main nerve involved being the right $N$. ulnaris. To a lesser extent the right median and radial 

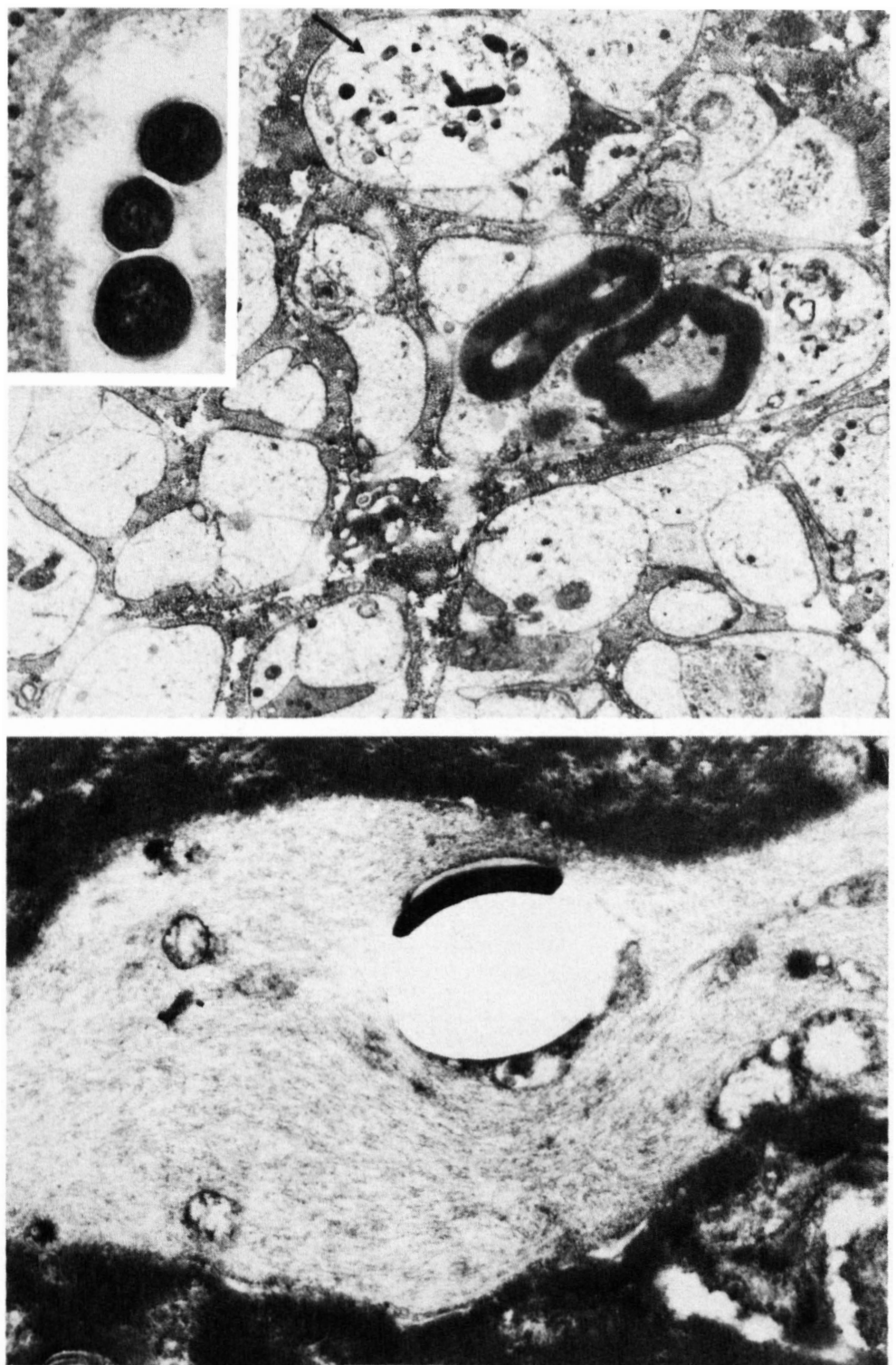

Figure 4 (a) Electron micrograph of a Schwann cell process with Mycobacteria inside. One Schwann cell process with two myelinated axons and debris $(\rightarrow)$. Proliferation of Schwann cell processes forming bands of Büngner, $(\times 11,200)$. Inset: Cross-section of viable Mycobacteria in a Schwann cell process $(\times 24,000)$. (b) A viable Mycobacterium with its electron-transparent zone (ETZ) inside a myelinated axon. $(\times 28,000)$.

nerve were also affected. Light and electron microscopical findings of the macroscopically most severely altered nerve regions revealed a borderline leprosy. ${ }^{3}$ Both tuberculoid changes (exudation of fibrin, epithelioid cells, segmental demyelination) and lepromatous changes (diffuse spread of lympho- 

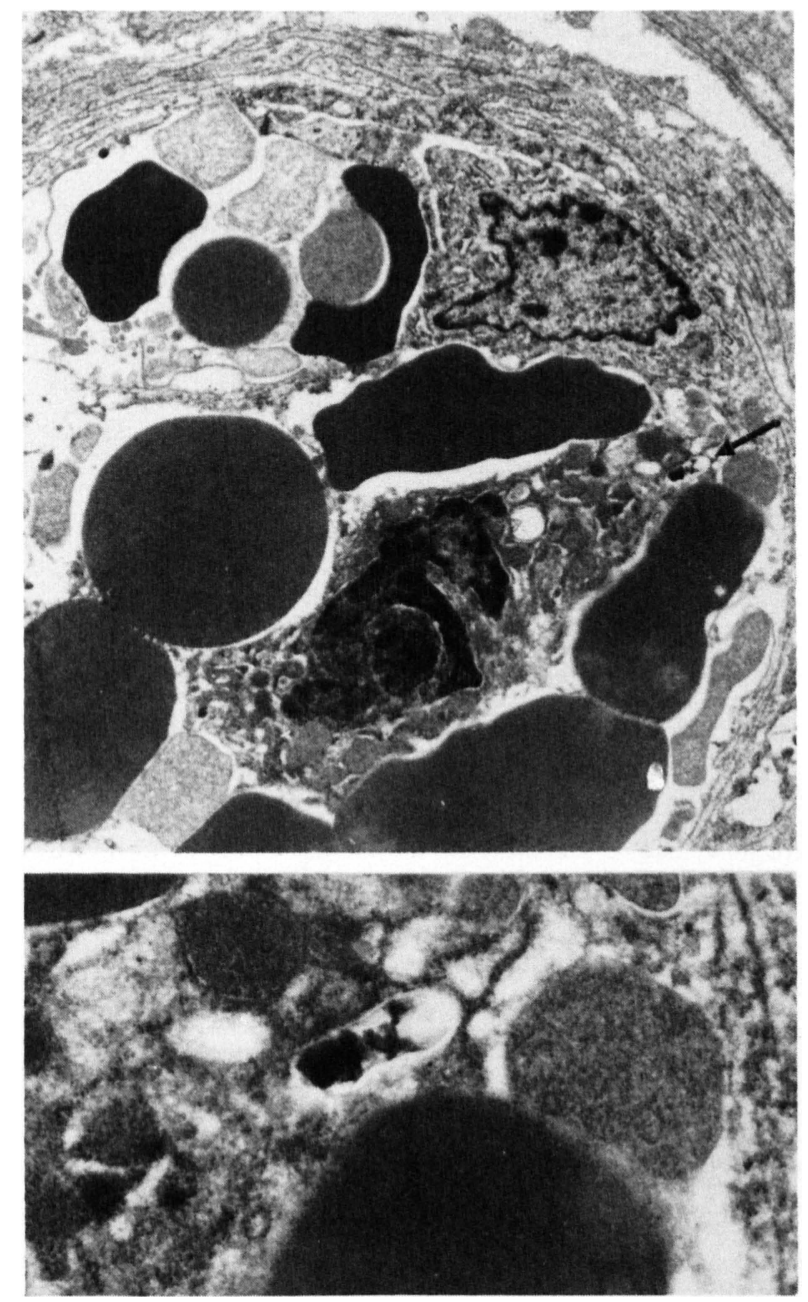

Figure 5 (a) Electron micrograph of a small vessel. Between erythrocytes and extruding from the vessel wall a large cell with a degenerated Mycobacterium $(\rightarrow) .(\times 7200)$. (b) Larger magnification of the above bacillus. $(\times 32,000)$.

cytes through the granuloma, foamy change of histiocytes, considerable bacterial load with intraaxonal bacilli) were present. Non-specific dermatitis in other body regions does not conflict with the classification, because even pure neural infections, in which there was as yet no apparent skin lesion, have been reported in all types of leprosy except LL. ${ }^{3}$

While the clinical history appeared to be short, histology indicated a rather advanced lesion. Neural elements were extensively destroyed and replaced by fibrous tissue. Preserved fascicles were distended by inflammatory cells, fibrin, oedema, and fibrous tissue.

In any type of leprosy the Schwann cell is considered to be the primary target 
of the mycobacteria.' Also in the present case the vast majority of them was found in these cells. Proliferation of Schwann cells and their processes was striking. In contrast, Wallerian degeneration was scarce. The prevailing segmental degeneration affected both unmyelinated and myelinated fibres. Thus an advanced stage of infection was indicated too. ${ }^{2}$

Despite the considerable bacterial load only few mycobacteria were seen in endothelial cells or in macrophages lying freely in vessel lumina. In a report on BB/BL-cases intraendothelial bacilli were commonly found in skin granulomata, but in endoneurial vessels they were observed in only $25 \%$ of the patients. Macrophage-enclosed bacilli in the lumina were not seen ${ }^{4}$ Their occurrence in this advanced case suggests that up-take of mycobacteria in endothelial cells of endoneurial vessels is a late-stage phenomenon. An intact 'blood-nerve-barrier' in earlier stages may prevent bacillary entrance to the endoneurial vessels, except as a rare event.

If endoneurial cells extruded into vessel lumina to such an extent that even platelet passage appeared impossible, luminal occlusion, as rarely seen in the present case, may take place. ${ }^{4,5}$

After experimental focal occlusion axonal swelling, oedema, patchy fibre degeneration, and endoneurial fibrosis have been observed.6,7 These changes, therefore, may also occur to some extent in leprous nerves, which already suffer from the non-specific vascular responses due to inflammation. The damage may be accentuated, if pressure by inflammatory cells inside the fascicles leads to further occlusion of vessel lumina. ${ }^{8,9}$

Inadequate nutrition by these vascular changes impairs regeneration of nerve fibres. This in our case is illustrated by only a few regenerative sprouts. Further inhibition is due to extensive endoneurial oedema. In an advanced case, like this, it is impossible to discriminate, to which proportion oedema is subsequent to leakage of 'blood-nerve-barrier'10,11 or to inflammatory exudation. But its pertinent inability to be properly drained by lymphatics leads to swelling of the nerve, distension of endoneurial fibres, and to endoneurial fibrosis later on. ${ }^{12}$

Swelling of the ulnar nerve by these processes may cause entrapment at its elbow sulcus as in the present case. This may aggravate the previous inflammatory lesion by further segmental demyelination and, in long-standing cases, also by axonal degeneration. ${ }^{13}$ As in general, pressure lesions may be either mechanical or ischaemic in leprosy too.

A mechanical factor is strongly suggested in our patient. In one area there was necrosis not only of neural tissue, but also of granulomatous and fibrous tissue. As there was no indication of a necrotizing reactional state, this necrosis, therefore, seems to be due to mechanical occlusion of supply vessels. This is an additional vascular contributor in leprosy, apart from the lumen occlusion mentioned above.

Leprosy bacilli have been observed in various cells: Schwann cells of unmyelinated and myelinated fibres, histiocytes, macrophages, fibroblasts, 
endothelial cells, and perineurial cells. ${ }^{2.14-17}$ In the present case the majority of bacilli were seen in Schwann cells and macrophages. On electron microscopy they were often degenerate and present within lysosome-like bodies. ${ }^{18}$ At times, these membrane-bodies only showed osmiophilic debris, suggestive of a previously viable form, which was taken up by a phagolysosome.

The electron-transparent zone (ETZ) around a bacterium, sometimes confluent around a clump of them, is most conspicuous and well defined in viable organisms. Thus, it is considered to be a product somehow dependent on an intact bacillary metabolism, since degenerative appearance of bacteria is usually associated with irregularity of the outer membrane and the ETZ itself. ${ }^{19}$ Bacterial degeneration must be due to the patient's immunological response. It cannot simply be attributed to treatment effects. For none of the borderline cases reported have received any antileprous treatment in the ten years before biopsy. ${ }^{14-16}$

Intra-axonal mycobacteria have been found to some extent in BL- and LL-patients. ${ }^{2,4}, 19-24$ None of these received any continuous treatment over a longer period of time. Early intra-axonal retrograde spread of bacteria has been correlated with disease untreated for more than one year. ${ }^{4}$ Our case, however, suggests that a considerably shorter clinical history may present with intra-axonal bacteria.

In agreement with the data of others intra-axonal bacilli were observed here in an advanced stage of borderline-leprosy with a heavy bacterial load. ${ }^{24}$ There must presumably be some damage to continuity of the axon so as to permit entrance of mycobacteria.

This is more probable in advanced lesions without previous therapy. The intra-axonal route might then be a mode of spread by sideways propagation: indeed, this may be inferred from the findings in the present case, since bacilli had apparently not affected the surrounding axoplasm.

\section{Acknowledgments}

This study is thankfully dedicated to $\mathrm{Dr} \mathrm{H}$. O. Lincke, Director of the Neurological Department, Municipal Hospital, Dortmund, Germany.

We gratefully acknowledge Professor Dr Racz of Hamburg for his cooperation; Mrs E Marczinczik, Mrs K Göpelt, Mrs M Roggendorf, Mrs C Wacker and $\mathrm{Mr}$ M Hebenstreit for their technical assistance; and Mrs A Rutberg for typing.

\section{References}

${ }^{1}$ Lumsden CE. Leprosy and the Schwann cell in vivo and in vitro. In Leprosy in Theory and Practice. 2nd ed. Cochrane RG, Davey TF (eds), Wright Bristol 1964, pp 221-50. 
2 Shetty VP, Mehta LN, Irani PF, Antia NH. Study of the evolution of nerve damage in leprosy. Part I-lesions of the index branch of the radial cutaneous nerve in early leprosy. Lepr India, 1980; 52: 5-18.

3 Ridley DS, Jopling WH. Classification of leprosy according to immunity. A five-group system. Int J Lepr, 1966; 34: 255-76.

${ }^{4}$ Boddingius J. Ultrastructural changes in blood vessels of peripheral nerves in leprosy neuropathy. II. Borderline, Borderline-lepromatous and lepromatous leprosy patients. Acta Neuropath, (Berl.), 1977; 40: 21-39.

5 Job CK. Mycobacterium leprae in nerve lesions in lepromatous leprosy: an electron microscopic study. Arch Path, 1970; 89: 195-208.

${ }^{6}$ Eames RA, Lange LS. Clinical and pathological study of ischaemic neuropathy. $J$ Neurol Neurosurg Psychiat, 1967; 30: 215-26.

7 Ashton N. The eye in malignant hypertension. Trans Am Acad Ophthal Otolar, 1972; 67: 17-40.

${ }^{8}$ Kaur S, Wahi PL, Chakravarti RN, Sodhi JS, Vadhwa MB, Thera AS. Peripheral vascular deficit in leprosy. Int J Lepr, 1976; 44: 332-39.

9 Carayon A, Languillon J, Giraudeau P, Camain R, Maydat L. Névrites micro-angiopathiques d'origine auto-immune probable aprés migrations inverses dans la zone borderline du spectre de la lèpre. Méd Tropicale, 1976; 36: 16-33.

${ }^{10}$ Olsson Y, Reese TS. Permeability of vasa nervorum and perineurium in mouse sciatic nerve studied by fluorescence and electron microscopy. J Neuropath Exp Neurol, 1971;30: 105-119.

1 Boddingius J, Rees RJW, Weddell AGM. Defects in the blood-nerve-barrier in mice with leprosy neuropathy. Nature (New Biol), 1972; 237: 190-91.

12 Krücke W. Ödem und seröse Entzündung im peripheren Nerven. Virch Arch Path, 1941/42; 308: $1-13$.

13 Neary D, Eames RA. The pathology of ulnar nerve compression in man. Neuropath Appl Neurobiol, 1975; 1: 69-88.

${ }^{14} \mathrm{Kahn} \mathrm{P}$, Scott T. The pathology of a radial nerve biopsy in leprosy: Light and electron microscopy. Amer J Path, 1973; 114: 97-100.

15 Finlayson MH, Bilbao JM, Lough JO. The pathogenesis of the neuropathy in dimorphous leprosy; Electron microscopic and cytochemical studies. J Neuropath Exp Neurol, 1974; 33: 446-55.

${ }^{16}$ Mehta LN, Shetty VP, Antia NH, Irani PF. Quantitative, histologic and ultrastructural studies of the index branch of the radial cutaneous nerve in leprosy and its correlation with electrophysiologic study. Int J Lepr, 1975; 43: 256-64.

17 Schmitt J, Barrucand D, Floquet J, Floquet A, Schmidt C. Névrite hansénienne a forme pseudosyringomyélique. Rev Neurol (Paris), 1976; 132: 33-49.

18 Rees RJW, Valentine RC. The appearance of dead leprosy bacilli by light and electron microscopy. Int J Lepr, 1962; 30: 1-9.

19 Boddingius J. The occurrence of Mycobacterium leprae within axons of peripheral nerves. Acta Neuropath. (Berl.) 1974; 27: 257-70.

${ }^{20}$ Mitsuda K. On the leprous lesions of peripheral nerves and blood vessels. Papers on leprosy by Kensuke Mitsuda. Okayama Chotaki Foundation, 1935; 1: 1-11.

${ }^{21}$ Khanolkar VR. Studies in the histology of early lesions in leprosy. Indian Council of Med Res Spec Rep Ser, 1951; 19: 1-18.

22 Nishiura M, Harada N, Imaeda T. Electron microscopy of ultrathin sections of lepromatous peripheral nerves. Int J Lepr, 1957; 25: 323-27.

23 Imaeda T, Convit J. Electron microscopic study of cutaneous nerves in leprosy. Int J Lepr, 1963; 31: 188-209.

24 Yoshizumi M, Asbury AK. Intra-axonal bacilli in lepromatous leprosy. Acta Neuropath. (Berl.), 1974; 27: 1-10. 
